\title{
The Proportion of BNP Decline after Left Ventricular Assist Device Implantation Predicts Length of Survival after Surgery
}

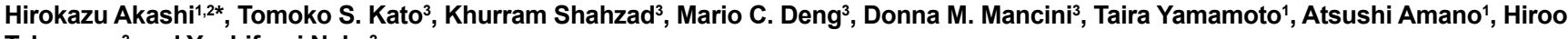
Takayama $^{2}$ and Yoshifumi Naka ${ }^{2}$

${ }^{1}$ Department of Cardiovascular Surgery, Juntendo University School of Medicine, Tokyo, Japan

${ }^{2}$ Department of Cardiothoracic Surgery

${ }^{3}$ Department of Cardiovascular Medicine, Columbia University Medical Center, New York, USA

\begin{abstract}
Object: Differences in B-type natriuretic peptide (BNP) values before and after left ventricular assist device (LVAD) surgery were evaluated as a predictor of survival after the surgery.

Background: The impact of reduction of pre-operative BNP values, following LVAD surgery, on post-operative survival in heart failure (HF) patients is not known.

Methods: Among a total of 287 patients who underwent LVAD surgery at Columbia University Medical Center between 2000 and 2010, 72 patients who had plasma BNP measurements at both 1 week before and 1 month after surgery were enrolled. Patients were divided into 2 groups according to $\%$ change of BNP value through surgery $(\%$ BNP change): greater (group A) or less than (group B) the median \% BNP change.

Result: Neither pre-operative nor post-operative BNP values were significantly correlated with post-surgical survival. The \% BNP change was significantly correlated with post-surgical survival. Clinical characteristics, laboratory examination, and hemodynamics before and after surgery were not different between the two groups. Group A patients showed significantly better survival at 100 and 200 post-surgical days compared to group B $(86.1 \%$ vs. $74.6 \%, 80.6 \%$ vs. $54.5 \%, p=0.0399$, respectively).
\end{abstract}

Conclusion: The \% BNP change could predict survival after LVAD surgery.

Keywords: LVAD; BNP; Survival after LVAD surgery

\section{Introduction}

Plasma B-type natriuretic peptide (BNP) values have been evaluated as predictors of outcome and are helpful in determination of therapeutic options $[1,2,3]$ in patients with both acute and chronic heart failure (HF). In a Val-HeFT trial, patients with higher plasma BNP concentration showed a significantly higher mortality compared with those with lower plasma BNP concentration [4]. Comprehensive review of BNP value related heart failure studies has shown that BNP value can be used for estimation of relative risk of death or cardiovascular events in patients with HF. Plasma BNP value has been also reported to be a better predictor of survival than are traditional risk factors such as NYHA class [5]. Plasma BNP value was also reported to reflect the effect of therapy [6]. It has been reported that optimization of medical therapy was associated with significant reductions in plasma BNP value [1]. However, regarding patients with severe HF following left ventricular assist device (LVAD) surgery, the impact of reduction of the pre-operative BNP value on post-operative survival has not been investigated. In the present study, we retrospectively reviewed plasma BNP values in HF patients before and after LVAD surgery to determine whether the proportion of BNP decline was related to survival duration after surgery.

\section{Materials and Methods}

\section{Study design}

Among a total of 287 patients who underwent HeartMate XVE or II (Thoratec ${ }^{\circledR}$, USA) LVAD surgery between 2000 and 2010 at Columbia University Medical Center, 72 patients who had both pre-operative BNP measurements at 1 week prior to the surgery and post-operative BNP measurements at 1 month after surgery were included in this study. Due to the reason that we selected patients who underwent 1-month postoperative BNP measurements, patients who died within 1 month after surgery were not included.
The difference in plasma BNP values before and after LVAD surgery was calculated using the following formula:

$\%$ BNP change $=[($ Pre-LVAD BNP value, $\mathrm{pg} / \mathrm{mL})-($ Post-LVAD BNP value $\mathrm{pg} / \mathrm{mL})] /($ Pre-LVAD BNP value, $\mathrm{pg} / \mathrm{mL}$ ) 100 .

The median value of $\%$ BNP change was calculated, and the patients who had both pre- and post-operative BNP values were divided into 2groups according to whether their \% BNP change greater or less than the median \% BNP change. The patients who showed a \% BNP change greater than the median \% BNP change were assigned to group $\mathrm{A}$, and those with \% BNP change less than the median \% BNP change were assigned to group $B$.

Clinical characteristics, laboratory measurements and hemodynamic data were compared between the groups. The survival duration after the surgery was also compared. The end-point for survival in the present study included death, devise exchange and heart transplantation. Due to donor shortage in a recent era, patients becoming unstable condition irrespective of LVAD support can be upgraded as UNOS status $1 \mathrm{~A}$ and may undergo emergent

${ }^{*}$ Corresponding author: Hirokazu Akashi MD, Department of Cardiothoracic Surgery, Columbia University Medical School, 650 West $168^{\text {th }}$ Street, Room 807, New York, NY 10032, USA, Tel: 212-305-0712; E-mail: akashi@juntendo.ac.jp

Received November 09, 2010; Accepted December 24, 2010; Published December 30, 2010

Citation: Akashi H, Kato TS, Shahzad K, Deng MC, Mancini DM, et al. (2010) The Proportion of BNP Decline after Left Ventricular Assist Device Implantation Predicts Length of Survival after Surgery. J Steroids Hormon Sci 1:103. doi:10.4172/21577536.1000103

Copyright: ( $) 2010$ Akashi $\mathrm{H}$, et al. This is an open-access article distributed under the terms of the Creative Commons Attribution License, which permits unrestricted use, distribution, and reproduction in any medium, provided the original author and source are credited. 
Citation: Akashi H, Kato TS, Shahzad K, Deng MC, Mancini DM, et al. (2010) The Proportion of BNP Decline after Left Ventricular Assist Device Implantation Predicts Length of Survival after Surgery. J Steroids Hormon Sci 1:103. doi:10.4172/2157-7536.1000103

Page 2 of 4

transplantation; therefore, we considered transplantation as an endpoint.

\section{Statistical analysis}

Data are presented as means \pm SD. Normality was evaluated for each variable on the basis of normal distribution plots and histograms. Logarithmic transformation of the variables was performed as needed to improve normality. The correlation between postoperative BNP values and the duration of survival after surgery in all studied patients were analyzed by Pearson's correlation coefficient. Laboratory measurements and hemodynamic data before and after surgery of enrolled patients were compared with a Student's paired $t$ test. The comparison of clinical characteristics, laboratory data, and hemodynamic variables between group A and B were analyzed using Student's unpaired two-tailed $t$ test or chi-square analysis. Survival after LVAD surgery between group A and group B was compared using Kaplan-Meier analysis and log rank statistics. All statistical analyses were performed using the JMP 8.0 software (SAS Institute, USA).

\section{Results}

Clinical characteristics of all studied patients are shown in Table 1 . Two patients required temporary right ventricular support

\begin{tabular}{|c|c|}
\hline \multicolumn{2}{|l|}{ Parameter } \\
\hline Age at LVAD surgery (year-old) & $52.79 \pm 17.72$ \\
\hline Sex (Male, no of patients, $\%$ ) & $55(76.4 \%)$ \\
\hline BMI at the time of LVAD surgery $\left(\mathrm{kg} / \mathrm{m}^{2}\right)$ & $26.12 \pm 5.32$ \\
\hline LVEF by echocardiogram before surgery (\%) & $16.30 \pm 5.62$ \\
\hline $\begin{array}{l}\text { LVAD type (no of patients, } \%) \\
\text { HM XVE } \\
\text { HM II }\end{array}$ & $\begin{array}{l}14(19.4 \%) \\
58(80.6 \%)\end{array}$ \\
\hline $\begin{array}{l}\text { Complications after LVAD surgery } \\
\text { CVA post-operation (no of patients, \%) } \\
\text { Drive line infection (no of patients, \%) }\end{array}$ & $\begin{array}{l}11(15.6 \%) \\
11(15.6 \%)\end{array}$ \\
\hline Survival days after LVAD surgery (days) & $328.11 \pm 321.98$ \\
\hline $\begin{array}{l}\text { Outcome (no of patients, \%) } \\
\text { OHT } \\
\text { On LAVD } \\
\text { Death }\end{array}$ & $\begin{array}{l}30(41.7 \%) \\
38(52.8 \%) \\
4(5.5 \%)\end{array}$ \\
\hline
\end{tabular}

\section{Data are presented as mean \pm SD}

Abbreviations: LVAD, left ventricular assist device; BMI, body mass index; LVEF left ventricular ejection fraction; HM XVE, HeartMate XVE; HM $\alpha$, HeartMate $\alpha$; CVA, cerebrovascular accident; $\mathrm{OHT}$, orthotopic heart transplant

Table1: Clinical characteristics of enrolled patients.

\begin{tabular}{|l|l|l|l|}
\hline Parameter & Pre-operation & Post-operation & P value \\
\hline \multicolumn{4}{|l|}{ Laboratory data variables } \\
\hline Hct $(\%)$ & $33.61 \pm 6.44$ & $36.30 \pm 6.12$ & 0.2538 \\
\hline Plat $\left(\times 10^{4} / \mu \mathrm{L}\right)$ & $194.19 \pm 77.97$ & $202.72 \pm 72.60$ & 0.2203 \\
\hline T-bil $(\mathrm{mg} / \mathrm{dL})$ & $1.66 \pm 1.06$ & $1.06 \pm 1.32$ & 0.1079 \\
\hline D-bil $(\mathrm{mg} / \mathrm{dL})$ & $0.55 \pm 0.47$ & $0.37 \pm 0.82$ & 0.4562 \\
\hline BUN $(\mathrm{mg} / \mathrm{dL})$ & $33.21 \pm 16.05$ & $27.50 \pm 13.01$ & 0.3695 \\
\hline Cre $(\mathrm{mg} / \mathrm{dL})$ & $1.44 \pm 0.50$ & $1.41 \pm 0.58$ & 0.4343 \\
\hline Na $(\mathrm{mEq} / \mathrm{L})$ & $131.75 \pm 9.61$ & $132.08 \pm 8.36$ & 0.7745 \\
\hline K $(\mathrm{mEq} / \mathrm{L})$ & $4.18 \pm 0.53$ & $4.19 \pm 0.52$ & 0.5510 \\
\hline Alb $(\mathrm{mg} / \mathrm{dL})$ & $3.66 \pm 0.45$ & $4.07 \pm 0.62$ & 0.0019 \\
\hline BNP $(\mathrm{mg} / \mathrm{dL})$ & $1946.53 \pm 1311.01$ & $683.65 \pm 615.03$ & 0.0003 \\
\hline Hemodynamic variables & $3.28 \pm 0.86$ & $5.34 \pm 1.36$ & 0.001 \\
\hline CO $\left(\mathrm{L} / \mathrm{min} / \mathrm{m}^{2}\right)$ & $25.11 \pm 8.56$ & $12.69 \pm 5.28$ & 0.001 \\
\hline PAWP $(\mathrm{mmHg})$ & $36.47 \pm 10.37$ & $22.93 \pm 7.97$ & 0.0001 \\
\hline Mean PA (mmH) & $10.29 \pm 6.71$ & $8.02 \pm 4.75$ & 0.1120 \\
\hline RAP $(\mathrm{mmHg})$ & $76.32 \pm 11.82$ & $81.53 \pm 5.59$ & 0.2888 \\
\hline Mean AP $(\mathrm{mmHg})$ & $3.62 \pm 2.20$ & $2.16 \pm 1.15$ & 0.0003 \\
\hline PVR (wood) & $21.38 \pm 8.53$ & $14.56 \pm 4.03$ & 0.0002 \\
\hline SVR $($ wood) &
\end{tabular}

Data are presented as mean $\pm \mathrm{SD}$, unless otherwise indicated

Abbreviations: Hct, hematocrit; Plat, platelet count; T-bil, total bilirubin; D-bil, direct bilirubin; BUN, blood urea nitrogen; Cre, creatinine; Na, sodium; K, potassium; Alb, albumin; BNP, brain natriuretic peptide; $\mathrm{CO}$, cardiac output; PAWP, pulmonary atrial wedge pressure; PA, pulmonary artery pressure; RAP, right atrial pressure; $A P$, arterial pressure; PVR, pulmonary vascular resistance; SVR, systemic vascular resistance

Table2: Laboratory and hemodynamic variables before and after LVAD surgery.

\begin{tabular}{|c|c|c|c|}
\hline Parameters & Group A & Group B & P Value \\
\hline \multicolumn{4}{|c|}{ Clinical characteristics } \\
\hline Age (year) & $53.62 \pm 2.96$ & $56.04 \pm 2.96$ & 0.5653 \\
\hline Sex (Male/female) & $28 / 10$ & $27 / 7$ & 0.4042 \\
\hline $\mathrm{BMI}\left(\mathrm{kg} / \mathrm{m}^{2}\right)$ & $25.30 \pm 0.88$ & $26.90 \pm 0.88$ & 0.1931 \\
\hline $\mathrm{BSA}\left(\mathrm{m}^{2}\right)$ & $1.95 \pm 0.040$ & $2.00 \pm 0.040$ & 0.3658 \\
\hline \multicolumn{4}{|c|}{ Laboratory data before LVAD surgery } \\
\hline Hct (\%) & $33.49 \pm 1.08$ & $33.73 \pm 1.08$ & 0.8748 \\
\hline T-bil (mg/dL) & $1.79 \pm 0.18$ & $1.52 \pm 0.18$ & 0.2720 \\
\hline D-bil (mg/dL) & $0.61 \pm 0.08$ & $0.50 \pm 0.08$ & 0.3294 \\
\hline Cre $(\mathrm{mg} / \mathrm{dL})$ & $1.43 \pm 0.08$ & $1.46 \pm 0.08$ & 0.8179 \\
\hline $\mathrm{Na}(\mathrm{mEq} / \mathrm{L})$ & $131.39 \pm 1.61$ & $132.11 \pm 1.61$ & 0.7523 \\
\hline Alb (g/dL) & $3.63 \pm 0.08$ & $3.70 \pm 0.08$ & 0.5128 \\
\hline \multicolumn{4}{|c|}{ Laboratory data after LVAD surgery } \\
\hline Hct (\%) & $36.91 \pm 1.02$ & $35.69 \pm 1.02$ & 0.4010 \\
\hline T-bil (mg/dL) & $0.94 \pm 0.22$ & $1.178 \pm 0.22$ & 0.4405 \\
\hline D-bil (mg/dL) & $0.32 \pm 0.14$ & $0.408 \pm 0.14$ & 0.6572 \\
\hline Cre $(\mathrm{mg} / \mathrm{dL})$ & $1.39 \pm 0.10$ & $1.42 \pm 0.10$ & 0.8082 \\
\hline $\mathrm{Na}(\mathrm{mEg} / \mathrm{L})$ & $131.47 \pm 1.40$ & $132.69 \pm 1.40$ & 0.5388 \\
\hline Alb $(g / d L)$ & $4.09 \pm 0.10$ & $4.05 \pm 0.10$ & 0.8204 \\
\hline \multicolumn{4}{|c|}{ Hemodynamic variables before LVAD surgery } \\
\hline $\mathrm{CO}\left(\mathrm{L} / \mathrm{min} / \mathrm{m}^{2}\right)$ & $3.08 \pm 0.159$ & $3.474 \pm 0.159$ & 0.0846 \\
\hline PAWP $(\mathrm{mmHg})$ & $24.54 \pm 1.63$ & $25.68 \pm 1.63$ & 0.6217 \\
\hline Mean PA (mmHg) & $36.27 \pm 1.91$ & $36.69 \pm 1.94$ & 0.8771 \\
\hline $\operatorname{RAP}(\mathrm{mmHg})$ & $10.43 \pm 1.28$ & $10.14 \pm 1.28$ & 0.8752 \\
\hline Mean AP $(\mathrm{mmHg})$ & $76.38 \pm 1.98$ & $76.25 \pm 1.98$ & 0.9659 \\
\hline PVR (wood) & $3.89 \pm 0.42$ & $3.35 \pm 0.42$ & 0.3601 \\
\hline SVR (wood) & $21.71 \pm 1.63$ & $21.05 \pm 1.63$ & 0.7739 \\
\hline \multicolumn{4}{|c|}{ Hemodynamic variables after LVAD surgery } \\
\hline $\mathrm{CO}\left(\mathrm{L} / \mathrm{min} / \mathrm{m}^{2}\right)$ & $5.326 \pm 0.30$ & $5.364 \pm 0.32$ & 0.9319 \\
\hline PAWP (mmHg) & $11.81 \pm 1.12$ & $13.65 \pm 1.18$ & 0.2666 \\
\hline Mean PA (mmHg) & $21.95 \pm 1.71$ & $24.00 \pm 1.79$ & 0.4129 \\
\hline $\mathrm{RAP}(\mathrm{mmHg})$ & $7.130 \pm 0.98$ & $8.91 \pm 0.98$ & 0.2066 \\
\hline Mean AP $(\mathrm{mmHg})$ & $81.24 \pm 1.23$ & $81.84 \pm 1.30$ & 0.7376 \\
\hline PVR (wood) & $2.26 \pm 0.25$ & $2.047 \pm 0.27$ & 0.5580 \\
\hline SVR (wood) & $15.03 \pm 0.88$ & $14.03 \pm 0.93$ & 0.4397 \\
\hline \multicolumn{4}{|c|}{ Survival days after LVAD implantation } \\
\hline Survival (days) & $406.25 \pm 52.41$ & $249.97 \pm 52.41$ & 0.0386 \\
\hline
\end{tabular}

Data are presented as mean $\pm S D$, unless otherwise indicated

Abbreviations: BMI, body mass index; BSA, body surface area; Hct, hematocrit T-bil, total bilirubin; D-bil, direct bilirubin; Cre, creatinine; Na, sodium; Alb, albumin; $\mathrm{CO}$, cardiac output; PAWP, pulmonary atrial wedge pressure; PA, pulmonary artery pressure; RAP, right atrial pressure; AP, arterial pressure; PVR, pulmonary vascular resistance; SVR, systemic vascular resistance; LVEF, left ventricular ejection fraction

Table 3: Laboratory and hemodynamic variables before and after LVAD surgery.

at the time of surgery, but both patients were successfully weaned from this support. Correlation analysis of BNP measurements and post-LVAD survival duration revealed that neither pre-operative nor post-operative absolute BNP values were significantly correlated with survival. On the other hand, there was a correlation between $\%$ BNP change and survival $(r=0.52 \mathrm{p}=0.0345)$.

Table 2 summarizes the comparison of laboratory and hemodynamic data before and after surgery derived from 72 patients enrolled in this study. In each patient included in this analysis, the serum albumin concentration was significantly increased and the plasma BNP value was significantly reduced after LVAD surgery compared the values before surgery. Regarding hemodynamic variables, the cardiac output was increased after LVAD surgery compared with the values obtained before surgery; in contrast, mean pulmonary artery pressure, pulmonary artery wedge pressure, peripheral vascular resistance and pulmonary vascular resistance were significantly reduced after LVAD surgery when compared to the values obtained before surgery.

The median value of \% BNP change through the surgery was $63.8 \%$. Therefore, 36 patients who showed a \% BNP change greater than $63.8 \%$ were assigned to group $A$ and the remaining 36 patients showing \% BNP changes smaller than $63.8 \%$ were assigned to group B.

The comparisons of clinical characteristics, pre-operative and 
post-operative laboratory measurements and hemodynamic data between groups $\mathrm{A}$ and $\mathrm{B}$ are summarized in Table 3. Laboratory examination and hemodynamic variables showed no significant differences between the groups. However, the survival after LVAD surgery was significant longer in group A than in group B. Figure 1 shows Kaplan-Meier survival curves of the two groups. Survival after LVAD surgery was significantly higher in group A than in group B.

\section{Discussion}

In the present study, we found that (i) neither the absolute values for the pre-operative BNP value nor post-operative BNP values were correlated with survival duration after LVAD surgery, (ii) however, the $\%$ change BNP was correlated with survival after surgery, (iii) patients with a larger percentage of BNP decline survived longer than those with smaller BNP declines after surgery.

Many studies have shown the plasma BNP value to be a significant indicator for prognosis as well as being a useful tool for guiding appropriate treatment $[1,4,7]$. Doust et al reported that patients with continuously high BNP values, even after treatment, were at high risk of a further event $[5,8,9]$. However, the impact of BNP change after LVAD surgery on patients' survival has not yet been fully investigated. As far as we are aware, the present study is the first to evaluate the impact of BNP change before and after surgery on the prognosis of LVAD patients.

The BNP values tend to increase with age, even in a general population without any heart disease, and tend to be higher in women than in men. BNP values are also influenced by body mass index (BMI) and plasma BNP concentrations are often elevated in patients with renal insufficiency, whether or not they have clinically diagnosed HF $[10,11]$. The BNP value has been reported to show no correlation with the severity of HF in tremendously sick patients [12]. Therefore, the BNP value might not reflect the severity of HF across all patients, and sometimes inter-patients comparisons might be difficult. In contrast, intra-patient comparison would be more useful from the point of view of follow-up of each patient in a clinical setting. In the present study, we were successfully demonstrated the correlation between \% BNP change of intra-patients and their postoperative survival duration.

The hemodynamic improvement of intra-patients before and after LVAD implantation was excellent (Table 2), although the right atrial pressure was not significantly changed. The post-operative

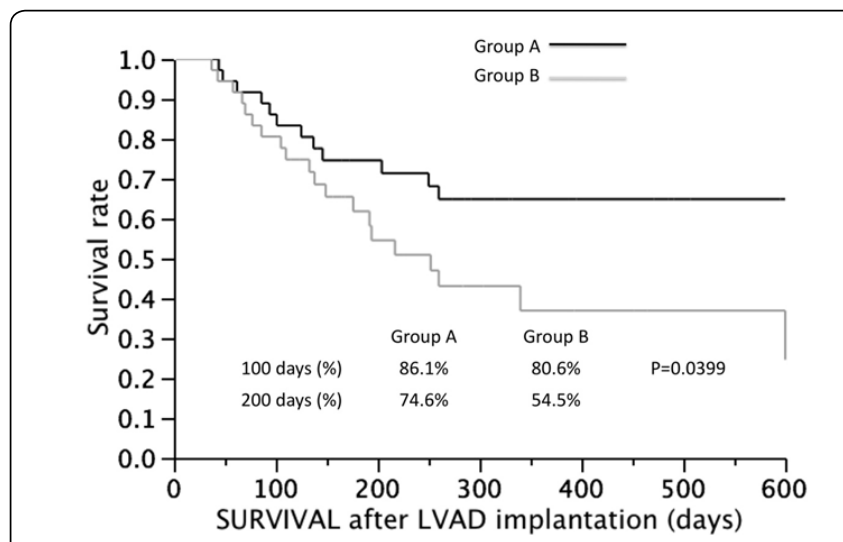

Figure 1: Kaplan-Meier survival curves for patients in groups $A$ and $B$. Survival rates of groups $A$ and $B$ at 100 and 200days after LVAD surgery. Solid line indicates group $A$ and dotted line indicates group $B$. right atrial pressure was slightly higher in group B than that in group A (Table 3), although this difference was not statistically significant. In other words, patients with smaller decline in BNP values through LVAD surgery (group B) may had have a tendency of being in a condition of persistently higher right atrial pressure. LVAD implantation could sufficiently unload the left ventricular end-diastolic pressure, and thus resulting in reduction of right ventricular afterload. However, even after the LVAD implantation, a certain amount of patients may demonstrated persistent high right atrial pressure after the surgery, especially who has smaller right ventricular pre-load reserve, We speculate that less BNP decline after LVAD surgery may be related to right heart failure.

We also speculate that persistent myocardial wall stress as reflected by smaller BNP decline through LVAD surgery in group B patient's affects lower survival rate in group B patients than that in group a patients. Further investigation would be required to confirm this possibility.

We calculated the correlation of pre- and post-operative BNP values and other non-cardiac variables, because the BNP values would be influenced by several factors other than HF. Pre-operative BNP values were statistically correlated with pre-operative BMI and blood urea nitrogen concentration, while post-operative BNP values and \% BNP change were correlated with post-operative serum creatinine values (data not shown). These results would be consistent with the idea that BNP values in each patient were affected by non-cardiac factors such as renal function, which would support our speculation that intra-patient rather than inter-patient BNP changes would more strongly predict each patient's prognosis.

The major limitation of this study is that we selected only patients who had plasma BNP measurements performed at both 1 week before and 1 month after the surgery. The reason why we selected a 1-month period of post-operative BNP measurements in this study was to avoid effects of surgical injury or heart-lung machine on BNP values $[13,14]$. We also wanted to obtain post-operative BNP values at the time when patients sufficiently recovered from the condition of preoperative cardiogenic shock. Previous study demonstrated that week to week change was sufficient to observe a mean $72 \%$ decrease in BNP values in heart failure patients undergoing appropriate treatment [15]. This patient-selection methodology might have caused a bias that would influence our results. In addition, the patients' cohort in this study was relatively very small. We also admit that the data were only available for limited time points because of the retrospective nature of the current study. We did not include patients who had pre-operative BNP measurement outside of our hospital, because BNP values can vary with the assay used [16]. Some results might also be quite different in a larger population. We further design a prospective study to collect multiple time points, which will lead to better understanding of the BNP relationship with patients' prognosis.

Another limitation of this study was that we did not consider the difference of LVAD type and its influence on BNP values. Further study would be necessary to evaluate the impact of LVAD type, such as pulsatile or non-pulsatile, on changes in BNP.

Despite several limitations, we still believe that we have achieved an excellent result of demonstrating prognostic value of BNP measurements in patients requiring LVAD surgery, which is worthwhile reporting. We expect that LVAD therapy becomes generally available in the near future. Therefore, we would like to provide our information is as described in this manuscript to not only doctors in cardiology field but also those working in a field of general 
Citation: Akashi H, Kato TS, Shahzad K, Deng MC, Mancini DM, et al. (2010) The Proportion of BNP Decline after Left Ventricular Assist Device Implantation Predicts Length of Survival after Surgery. J Steroids Hormon Sci 1:103. doi:10.4172/2157-7536.1000103

Page 4 of 4

patient care, who might refer their patients to the LVAD/transplant centers for further treatments.

This is a single-center, retrospective analysis of only a small number of patients who had both pre- and post-operative measurement of BNP values. In conclusion, the difference in BNP values before and after surgery could be a useful indicator for survival after LVAD surgery.

\section{Acknowledgments}

None of all authors has a financial relationship with a commercial entity that has an interest in the subject of the presented manuscript or other conflicts of interest to disclose.

\section{References}

1. Maeda K, Tsutamoto T, Wada A, Mabuchi N, Hayashi M, et al. (2000) High levels of plasma brain natriuretic peptide and interleukin- 6 after optimized treatment for heart failure are independent risk factors for morbidity and mortality in patients with congestive heart failure. J Am Coll Cardiol 36:1587-1593.

2. Richards AM, Doughty R, Nicholls MG, Macmahon S, Ikram H, et al. (1999) Neurohumoral prediction of benefit from carvedilol in ischemic left ventricular dysfunction. Circulation 99:786-792.

3. Fonarow GC, Peacock WF, Phillips CO, Givertz MM, Lopatin M, et al. (2007) Admission B-type natriuretic peptide levels and in-hospital mortality in acute decompensated heart failure. J Am Coll Cardiol 49:1943-1950.

4. Anand IS, Fisher LD, Chiang YT, Latini R, Masson S, et al. (2003) Changes in brain natriuretic peptide and norepinephrine over time and mortality and morbidity in the Valsartan Heart Failure Trial (Val-HeFT). Circulation 107:12781283.

5. Doust JA, Pietrzak E, Dobson, A Glasziou P (2005) How well does B-type natriuretic peptide predict death and cardiac events in patients with heart failure: systematic review. BMJ 330:625.

6. Wu, AH (2006) Serial testing of B-type natriuretic peptide and NTpro-BNP for monitoring therapy of heart failure: the role of biologic variation in the interpretation of results. Am Heart J 152: 828-834.
7. Logeart D, Thabut G, Jourdain P, Chavelas C, Beyne P. et al. (2004) Predischarge B-type natriuretic peptide assay for identifying patients at high risk of re-admission after decompensated heart failure. J Am Coll Cardio 43:635-641.

8. Troughton RW, Frampton CM, Yandle TG, Espiner EA, Nicholls MG, et al. (2000) Treatment of heart failure guided by plasma aminoterminal brain natriuretic peptide (N-BNP) concentrations. Lancet 355:1126-1130.

9. Murdoch DR, McDonagh TA, Byrne J, Blue L, Farmer R, et al. (1999) Titration of vasodilator therapy in chronic heart failure according to plasma brain natriuretic peptide concentration: randomized comparison of the hemodynamic and neuroendocrine effects of tailored versus empirical therapy. Am Heart $J$ 138(6 Pt 1): 1126-1132

10. Cataliotti A, Malatino LS, Jougasaki M, Zoccali C, Castellino P, et al. (2001) Circulating natriuretic peptide concentrations in patients with end-stage renal disease: role of brain natriuretic peptide as a biomarker for ventricula remodeling. Mayo Clin Proc 76:1111-1119.

11. Mueller C, Laule-Kilian K, Scholer A, Nusbaumer C, Zeller T, et al. (2005) B-type natriuretic peptide for acute dyspnea in patients with kidney disease: Insights from a randomized comparison. Kidney Int 67:278-284.

12. De Lemos, JA, McGuire, DK, Drazner, MH. B-type natriuretic peptide in cardiovascular disease. Lancet 2003; 362:316-322.

13. Mair P, Mair J, Bleier J, Hormann C, Balogh D, Puschendorf B. (1997) Augumented release of brain natriuretic peptide during reperfusion of the human heart after cardioplegic cardiac arrest. Clin Chim Acta 261: 57-68

14. Morimoto K, Mori T, Ishiguro S, Matsuda N, Hara Y, Kuroda H. (1998) Perioperative changes in plasma brain natriuretic peptide concentrations in patients undergoing cardiac surgery. Surg Today 28: 23-29

15. Wu AH (2006) Serial testing of B-type natriuretic peptide and NTpro-BNP for monitoring therapy of heart failure: the role of biologic variation in the interpretation of results. Am Heart J 152:828-834.

16. Redfield MM, Rodeheffer RJ, Jacobsen SJ, Mahoney DW, Bailey KR, et al. (2002) Plasma brain natriuretic peptide concentration: impact of age and gender. J Am Coll Cardiol 40:976-982. 